\title{
A NEW PHYLOGENETIC HYPOTHESIS FOR THE EVOLUTION OF POST- TRIASSIC NAUTILOID CEPHALOPODS
}

WARD*, Peter D., Department of Geological Sciences, the University of Washington, Seattle, Wa. 98195; SAUNDERS, W. Bruce, Dept. Geology, Bryn Mawr College, Bryn Mawr, Pa. 19010

Previous classifications of the Nautilacea have relied on suture pattern and shell ornamental characters to differentiate genera. In this paper we propose a multi-character system which uses shell coiling-, sutural and septal-, shell ultrastructure-, and pre-hatching shell characters as the bases for classification. Twenty-two such characters have been employed in a phylogenetic (parsimony) analysis of fourteen Upper Triassic to Recent nautiloid genera, resulting in a single most parsimonious tree. Combining this result with new discoveries of stratigraphic ranges for key genera, most notably Nautilus, allows construction of an evolutionary tree featuring a new phylogenetic hypothesis for the group: Nautilus, until now universally considered the last evolved member of the superfamily Nautilacea, is found to be ancestral to at least five Cretaceous and Tertiary genera. Our revised understanding of nautiloid phylogeny allows new insight into adaptive radiation following the end-Triassic and end-Cretaceous mass extinctions. In the first of these, both nautiloids and ammonites suffered nearly total extinction, with but a single genus of each surviving. The extinction pattern of the $\mathrm{K} / \mathrm{T}$ was somewhat different, in that all ammonites went extinct, but a much lower proportion of nautiloids suffered extinction. In both cases, nautiloids showed a pronounced rebound effect. 